Please cite this post-print as:

Nicholas, D., Rowlands, I., Jubb, M., and Jamali, H. R. (2010), "The impact of the economic downturn on libraries: With special reference to university libraries", Journal of Academic Librarianship, 36 (5), 376-382.

DOI: 10.1016/j.acalib.2010.06.001

Published version: http://dx.doi.org/10.1016/j.acalib.2010.06.001

\title{
The impact of the economic downturn on libraries: with special reference to university libraries
}

\section{David Nicholas}

Director of CIBER (Centre for Information Behaviour and the Evaluation of Research) and Professor at and Director of the Department of Information Studies, University College London.

CIBER, Department of Information Studies, University College London, Henry Morley Building, Gower Street, London WC1E 6BT. Email: david.nicholas@ucl.ac.uk

Address: CIBER, Department of Information Studies, University College London, Henry Morley Building, Gower Street, London WC1E 6BT

Tel: +442076792107

Fax: +44 2073830557

Email: david.nicholas@ucl.ac.uk

\section{Ian Rowlands}

Cofounder of CIBER, Reader at the Department of Information Studies, University College

London.

Address: CIBER, Department of Information Studies, University College London, Henry Morley Building, Gower Street, London WC1E 6BT.

Tel: +442076792107

Fax: +44 2073830557

Email: i.rowlands@ucl.ac.uk

\section{Michael Jubb}

Director of Research Information Network (RIN)

Address: Research Information Network, 96 Euston Road, London NW1 2DB, UK

Tel: +44 (0)20 74127285

Email: michael.jubb@rin.ac.uk

\section{Hamid R. Jamali}

CIBER research associate, and Assistant Professor, $\mathrm{PhD}$; 
Address: CIBER; Department of Library and Information Studies, Faculty of Psychology and Education, Tarbiat Moallem University, No 49, Mofateh Ave, P.O.Box: 15614,

Tehran, Iran

Email: h.jamali@gmail.com

Tel: +989127248119

\begin{abstract}
Evidence is presented of the extent to which libraries from around the world are experiencing financial hardship as a result of the word-wide economic downturn. Comparative analyses are provides on the grounds of country, sector and size of institution. The article concentrates on the situation of UK and US university libraries and is based on the findings of two research projects: 1) a global questionnaire survey to which more than 800 institutions responded; 2) a focus group study involving 16 UK university librarians.
\end{abstract}

\title{
Introduction
}

Libraries have for long played a central role in the lives of universities, in supporting learning, teaching and research. Along with the rest of the higher education sector they have experienced over the past decade a period of unprecedented growth and change. It is widely recognised that they have transformed their operations as they have responded to the opportunities presented by the digital revolution. Like the rest of the sector, however, academic libraries are now facing a renewed and intensified period of financial stringency. Alarm bells have started ringing and in recent months, a number of bodies, including the American Library Association (2010), UKSG (2009), and JISC (2009) have been gathering evidence about the nature and scale of the financial and other challenges that libraries are facing in these new challenging times.

This paper moves the research on by providing a global perspective, making comparisons with what is occurring in libraries serving other sectors and by examining in detail, and in context, what is happening on the ground in UK university libraries. The data for the paper comes from two recent studies, one, a general, global study from the Charleston Observatory, the research arm of the Charleston Library Conference ${ }^{1}$, and the other, a follow-up study concentrating on UK university libraries funded by the Research Information Network ${ }^{2}$. The Charleston survey was the result of a poll of conference delegates and members of the email lists of the study's sponsors - ebrary and Taylor and Baker, asking them what library topic concerned them most. More than two hundred librarians from around the world responded and the impact of the economic downturn on libraries was their resounding response. The much-talked-about severe economic, political, social and educational challenges (the 'perfect storm') that libraries, especially academic ones, are facing was clearly concentrating their minds when making the selection ${ }^{3}$. The specific aims of the Survey were to: a) establish the extent of any downturn throughout the world; b) examine the changes that libraries are making in the context of the economic downturn: where budgets and resources are being focused and why; c) determine what practical and positive things are being done to deal with the downturn; d) assist the community as a whole by increasing co-operation and transparency, sharing best practice, and identifying priorities. 
The general aim of the RIN project, a focus group based-study, was essentially to follow-up the findings of the Charleston survey, which covered 64 UK universities, with in-depth discussions with university librarians in the UK; this in order to test and gain reactions to the Charleston survey's findings, to obtain a deeper understanding of the situation, and to establish what practical steps librarians were taking.

\section{Methodology}

\section{a) Charleston survey}

Questions for the survey were selected, formulated and piloted with the help of Elsevier, The Charleston Conference, ebrary and Baker \& Taylor, and previously published surveys ${ }^{4}$. The questionnaire was mounted on Survey Monkey and the email lists of the aforementioned organisations were used to make librarians aware of the questionnaire. The questionnaire remained online during October 2009. Altogether 835 institutions responded (responses were limited to one per institution to prevent duplication). The majority of respondents originated from the USA (62.3\%), which was followed by the UK $(12.7 \%)$. Europe $(20.7 \%)$, excluding the UK, and the rest of the world (12.3\%) were underrepresented, mainly as the result of the survey being conducted in English. However, analysis of the responses across many of the variables shows striking consistency, regardless of geographic region. Where there are striking geographical differences they are highlighted in this paper. The survey included responses from universities, further education and community colleges, high schools and secondary schools, national libraries, government agencies, public libraries, hospitals and corporations. Most (76.8\%) of the responses were from academic institutions; and almost two-thirds of them (63.6\%) were from university libraries, which are the prime focus of this paper. The public sector and Government accounted for $14.1 \%$ and corporate bodies accounted for the rest $(9.1 \%)$. Institutions were asked to place themselves in ten size bands according to the number of registered library users they serve. Eleven per cent were large (more than 40, 000 users); $48 \%$ were medium (5,000-39,999 users); and the rest small libraries with up to 4,999 users. Where major differences relate to size of library, they are highlighted in this paper.

The questionnaire data were analysed using SPSS.

\section{b) RIN focus groups}

Sixteen Library Directors from a representative range of English universities took part in 3 focus groups, held during November 2009 in Birmingham, Manchester and London, at which they were asked to consider the Charleston and other evidence in the light of their own experience.

\section{Findings}

The discussion of the findings of the two studies is conducted along the following broad lines; first, where appropriate, the situation for libraries in all sectors across the world is outlined, based on the tabulated Charleston questionnaire data, to provide a context for the examination of the position of university libraries in particular; second, using the same dataset, the global university situation is outlined and then detailed comparisons are made between UK and US universities; third, the particular situation in the UK is explored using data the RIN focus groups. . 


\section{The Financial Position}

The current year

The Charleston questionnaire asked librarians to compare their total library budget (including staffing, resources and operational costs) for the current financial year with that for the previous year. Since this was a global survey and there are so many potential measures of 'inflation', respondents were asked to compare absolute figures. The picture that emerges (Table 1) is one of mixed fortunes, with a minority of respondents experiencing budget uplift, as much as $17.7 \%$ of public sector libraries. Most libraries either have a standstill budget (no allowance for inflation) or cuts, and in around a quarter of cases these are severe, being in the order of 10 per cent or more. Academia is the worst hit sector, with $43.8 \%$ libraries saying they are down on the previous year, and the corporate sector the least hit, with 'just' $36 \%$ experiencing cuts.

For UK university libraries the picture is mixed, with $36 \%$ of libraries stating their budget (excluding inflation) is similar to the previous year's, 29\% stating it is up, and the rest $(35 \%)$ reporting cuts. The comparative situation for US university libraries is markedly worse, with $42 \%$ reporting a steady state, $22 \%$ saying they are experiencing a rise, and $44 \%$ experiencing cuts.

Table 1: Total budget change for this year compared with the previous year. Charleston Observatory 2009 ( $n=663$ global)

\begin{tabular}{|l|c|c|c|}
\hline & Academic & $\begin{array}{c}\text { Public sector and } \\
\text { government }\end{array}$ & Corporate \\
\hline $\begin{array}{l}\text { More than 10\% } \\
\text { down }\end{array}$ & 27.0 & 27.0 & 24.6 \\
\hline $\begin{array}{l}\text { Less than 10\% } \\
\text { down }\end{array}$ & 16.8 & 9.4 & 11.4 \\
\hline About the same & 39.4 & 45.9 & 50.9 \\
\hline Less than 10\% up & 13.0 & 11.8 & 11.3 \\
\hline $\begin{array}{l}\text { More than 10\% } \\
\text { up }\end{array}$ & 3.6 & 5.9 & 1.9 \\
\hline
\end{tabular}

The financial picture for the current year that emerged from the focus groups with UK university librarians is similar to that found in the survey, and was very mixed. A number of universities have supported their libraries with additional funding (as much as $18 \%$ in one case), while others have imposed cuts of $10 \%$ or more. A number of factors explain why some libraries are experiencing real financial pain while others are experiencing growth. Most significantly, the minds of senior university managers were increasingly concentrating on the quality of the 'student experience', partly as a result of the wide publicity given to the results of the National Student Survey (NSS), which has provided the students with a powerful consumer voice. Because they (or their parents) are paying fees, students expect value for their money, and libraries are one of the most obvious 
things on their value-for-money tick list. Thus one library at a teaching-intensive university found itself saved from a $6 \%$ cut, which the rest of the university was experiencing, because the library obtained very poor results in the NSS. The ViceChancellor felt that the university had to invest in the library to improve the score. Other factors which have saved libraries from being cut so far included sympathetic and supportive Vice-Chancellors, an understanding among senior university management of what the library budget delivers, and the research agenda to which it was though libraries could contribute.

\section{The Future}

What then of the coming year's financial prospects? Here too the results of the survey showed a mixed picture, with a majority of libraries facing another standstill budget or further cuts (Table 2). Again, academic libraries are the hardest hit, with $39.7 \%$ facing the prospect of a cut, although recessionary pressures were being felt in all sectors. Corporate libraries fare the best, but even so nearly a quarter $(23.5 \%)$ face real cuts. The bleak vision of the future for UK university libraries is reflected in the $55 \%$ of respondents who reported cuts for the coming year, as compared with $41.8 \%$ of US university librarians who are expecting cuts.

Table 2: Total budget change for the next financial year, compared with this year [not allowing for inflation]. Charleston Observatory 2009 ( $n=649$ global)

\begin{tabular}{|c|c|c|c|}
\hline & Academic & $\begin{array}{c}\text { Public sector and } \\
\text { government }\end{array}$ & Corporate \\
\hline $\begin{array}{c}\text { More than 10\% } \\
\text { down }\end{array}$ & 18.1 & 19.1 & 13.7 \\
\hline $\begin{array}{c}\text { Less than 10\% } \\
\text { down }\end{array}$ & 21.6 & 10.8 & 9.8 \\
\hline About the same & 47.5 & 53.6 & 52.9 \\
\hline Less than 10\% up & 9.7 & 13.1 & 15.6 \\
\hline $\begin{array}{c}\text { More than 10\% } \\
\text { up }\end{array}$ & 3.1 & 3.6 & 7.9 \\
\hline
\end{tabular}

What then of the prognosis beyond the following year - two years down the line (not allowing for inflation)? There was clear differences here: UK librarians were very pessimistic, with $48 \%$ anticipating that in two years' time their budget will be down on what it is now, the rest of the world relatively bullish (only $21 \%$ thought so) and the US (36\%) somewhere in between. UK university librarians were even more pessimistic, with $56.9 \%$ thinking they would be down in two years time. US university librarians, by contrast, were a little less pessimistic than their colleagues in other sectors: only 33\% thought they would be down. 
The long-term pessimism of UK librarians was evident in the focus groups. Most UK universities are seeking to reduce library budgets over the next three years by between $5 \%$ and $10 \%$ a year, and in addition most libraries just have to take publisher inflation and currency fluctuations on the chin. Library directors were forthright in their opinion that such cumulative cuts could not be met simply by seeking more of the kinds of efficiency savings they have been making over the past decade; there is little fat to cut any more.

Participants felt that what was being experienced now was something different; not just a passing blip which would see things back to normal in a few years time. What was thought to be unusual this time was the coming together of so many factors - political, economic, social and educational - and this was all conspiring to create a 'perfect storm'. There were so many imponderables. What will the future of the university sector look like? Will some institutions fail? Will smaller institutions be forced into mergers? Will some universities go private? Then they had to factor in the uncertainty over student fees, the General Election and the digital transition. Libraries were prisoners of events over which they had little control.

There was a consensus that universities libraries had experienced ten golden years when they were seen to deliver much in regard to digital and remote access, and as a result had really changed academics' lives ('a quantum leap in provision' as one participant put it) 5 . The prevailing mood was that the golden age would not return and that the golden goose had laid its last egg. Librarians were not sure what the next trick would be or whether there were any more tricks left. One librarian what said that what they do now would constitute the last throw of the dice; many others said this is or should be time for restructuring and re-engineering.

\section{Changes in patterns of library spending}

Libraries were asked in the survey to estimate how their patterns of spending were likely to change over the next two years (Figure 1). Their answers once again revealed a complex picture, with a range of scenarios on offer. Much of the financial pressure will be absorbed through reduced spending on information resources: $69.1 \%$ of respondents expect to spend the same or less than they do today ('the same' amounts to a cut as the figures contain no provision for inflation). Staffing budgets also look vulnerable at many (but not all) institutions: $30.5 \%$ of all librarians believe they will be cut here. Relatively speaking, library services and infrastructure are the most protected budget lines.

Figure 1: The financial outlook: changes in spending plans. Charleston Observatory 2009 ( $n=649$ global) 


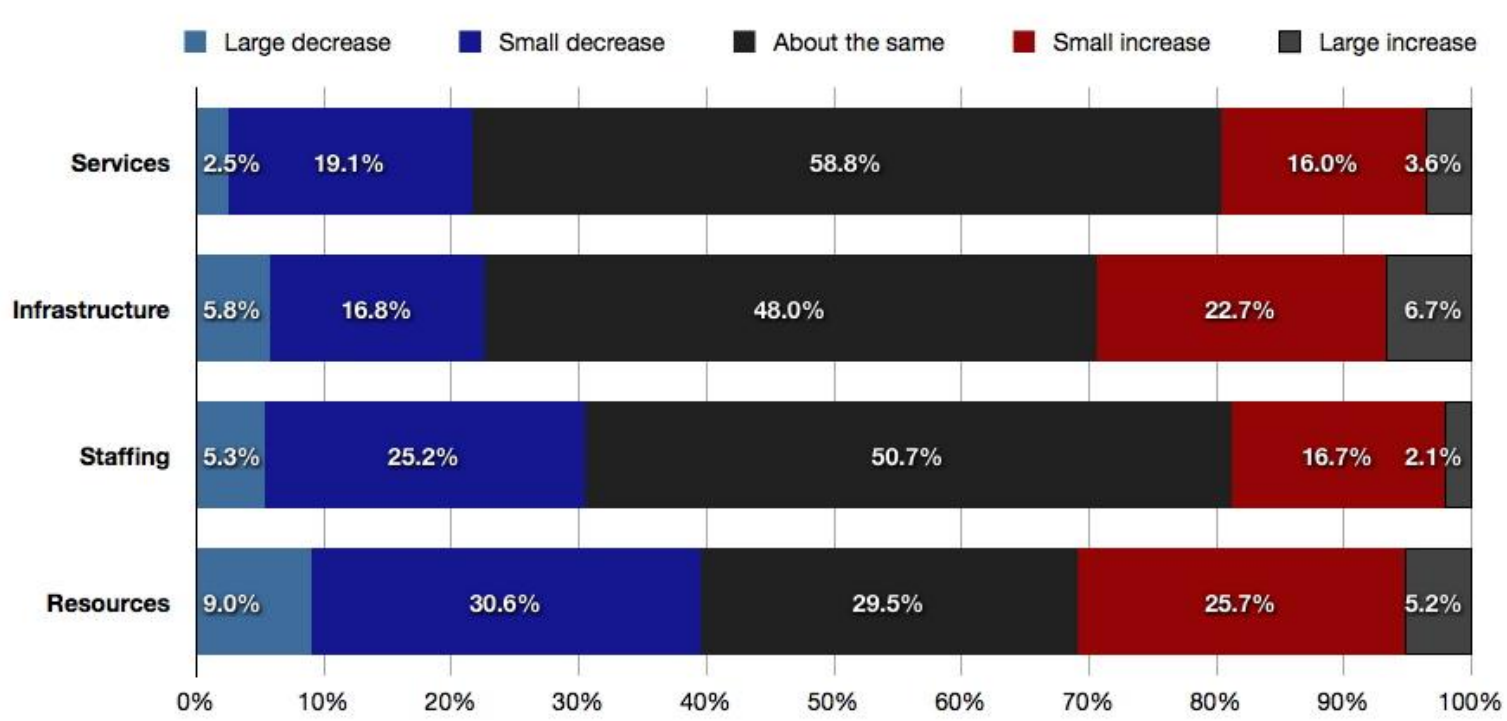

The UK university librarian focus groups showed that the balance of expenditure varies considerably across the HE library sector, in accordance with the varying missions of their host institutions, as well as for historical reasons. The proportion of library budgets devoted to the acquisition of books, serials and other information resources averages around $36 \%$, but there is considerable variation around that mean, from under $20 \%$ to well over $50 \%$. The other major category of expenditure is on staff, and the proportions here vary similarly, from around $30 \%$ to over $70 \%$ in some small specialist institutions.

\section{Information resources}

Figure 2 shows how, on average, academic, public sector and corporate libraries apportioned their spending on information resources in the current financial year. There are clear sectoral differences, as would be expected, with journals (in all formats, print, electronic and both) occupying a central position in academic and corporate libraries, while print books feature most strongly in the budgets of public institutions. E-books currently account for a small proportion of total spending, but this figure is rising fast from a late start. Clearly e-books offer an opportunity for business model innovation for all the stakeholders.

With $36.8 \%$ of the sample spending more than US\$1 million on information content, and $6.8 \%$ spending more than US $\$ 8$ million, this is a huge expenditure area. Interestingly, information content in electronic formats accounts for $57.2 \%$ of library resource budgets in the current year.

\section{Figure 2: Current balance of expenditure on information resources Charleston Observatory 2009 ( $n=649$ global)}




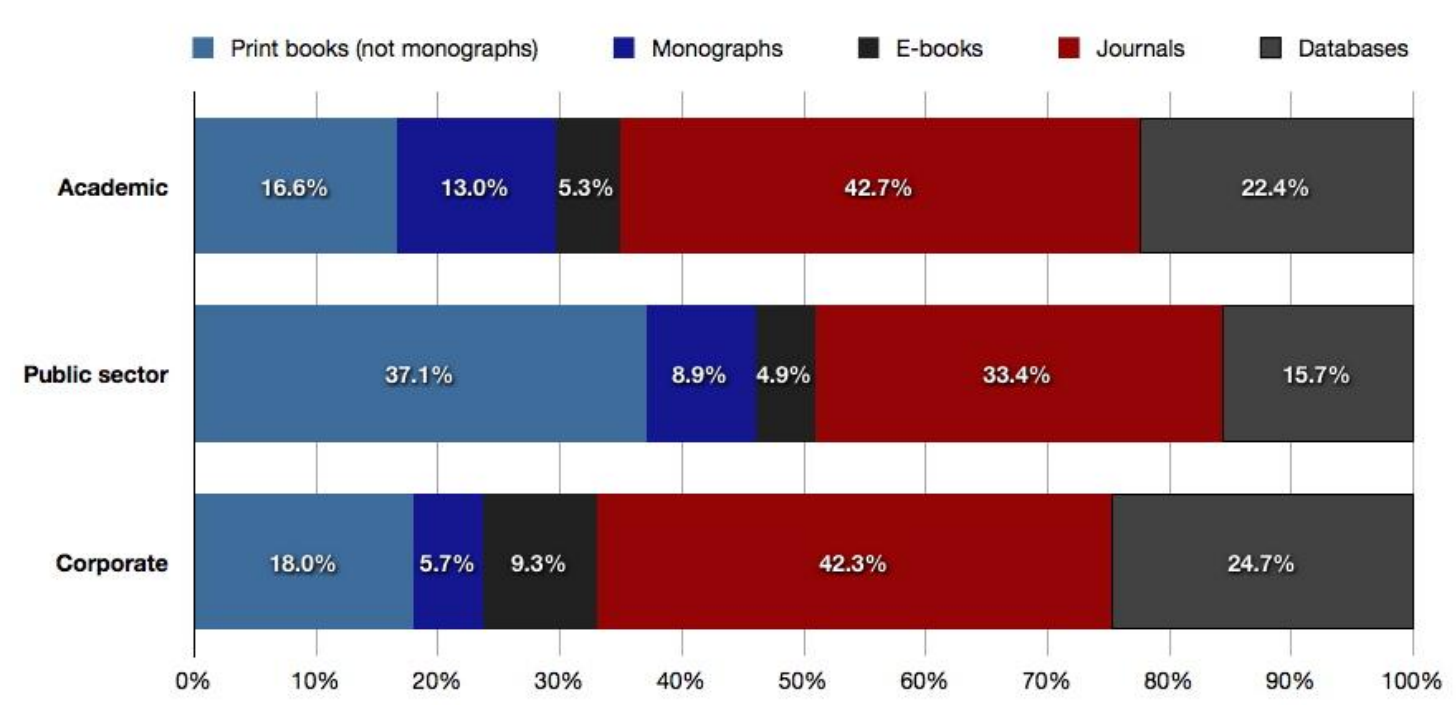

Not surprisingly, then, , more institutions (37.4\%) are actively planning to reduce their spending on information resources, as distinct from staffing and services, over the next two years. A small majority $(54.8 \%)$ of large libraries (with more than 40,000 users) are planning to cut information resources, compared with only $26.8 \%$ in the case of small libraries (less than 5,000 users). There were no clear geographical patterns: once again, library size and sector seemed to be the determining factors. Academic libraries were most likely to say they would cut their information resources, with $40.3 \%$ saying so; and the corporate sector least likely (24\%). Among university libraries, the UK ones are more likely to cut in the resource area over the coming two years, with $50.9 \%$ saying so, as compared to $46.9 \%$ for American universities. However, the real difference was in the proportion expecting large decreases in funding, $15.1 \%$ in the UK and $8.1 \%$ in the US.

How then are university libraries going to manage information resource cuts over the next two years? Figure 3 gauges the pressure on various types of information resource on a four-point scale where 4 is 'very likely', 3 is 'likely', 2 is 'unlikely' and 1 is 'very unlikely'. The bars show the average ratings on this scale for different types of information resource. Clearly, all formats are under pressure, especially print-only journals and print books and monographs. Print formats appear to be slightly more protected in large libraries, although this is not statistically significant. UK university libraries are likely to cut all types of resource more than their US counterparts, with the important exception of e-books.

Figure 3: Managing information resources cuts over the next two years $(n=360$ US/UK academic libraries) 
Print books (not monographs)

Monographs

E-books

Print only journals

E-only journals

Print/electronic journals

Databases

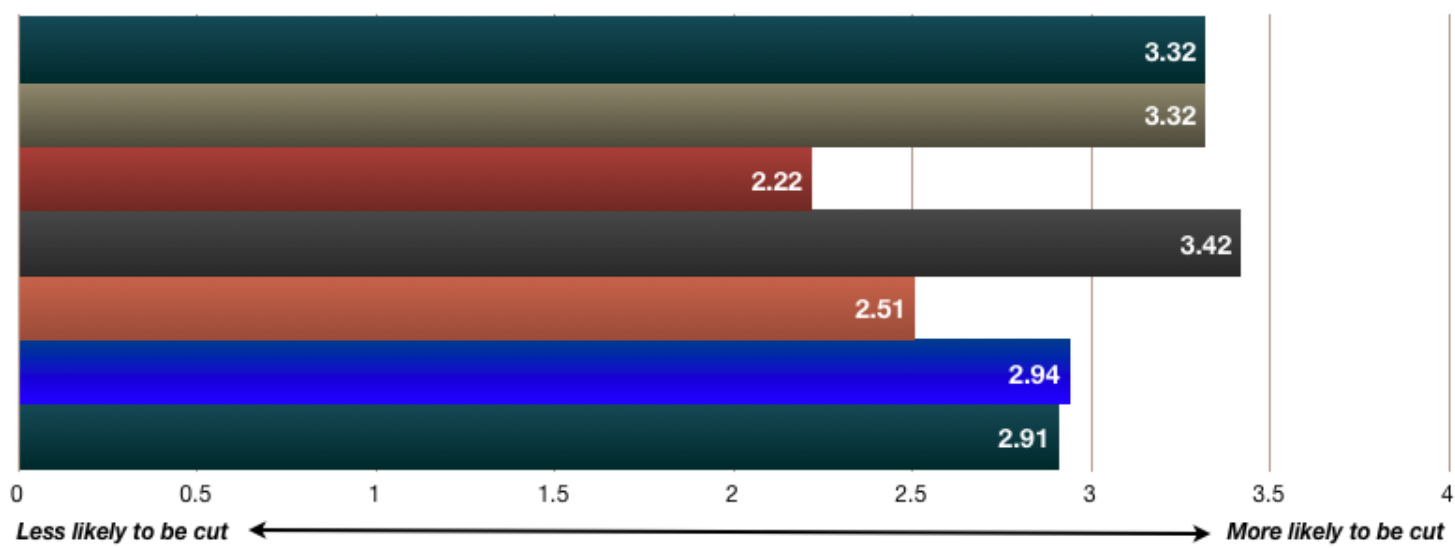

\section{Journals}

Journals in both formats and database subscriptions look fairly vulnerable. This is not surprising as they are a natural target because of their considerable cost (sometimes the biggest item on the library budget), and the inflationary nature of Big Deals (as one focus group participant said 'Big Deals bring with them guaranteed price increases'). The focus groups highlighted a wide range of concerns about the Big Deals as they currently operate in the UK, with many of the deals negotiated centrally by JISC, and universities then invited to opt in at prices dependent on their size. Some librarians are considering dealing with publishers direct, in an attempt to get better terms. Others, from the full range of universities, are considering cancelling one or more of their current deals. Most libraries are monitoring use closely, and one library found that as many as a quarter of Big Deal titles are used fewer than six times a year. At the very least, pressure to cancel such low-use titles is immense.

But many librarians are also worried that cancellations of Big Deals in total might play into the hands of publishers, and that they would be picked off one by one by publishers who are monopoly suppliers of content that their users want. One librarian who had been involved in negotiating Big Deals warned that publishers have much better data and information than librarians, and can use this to their advantage. Hence there is also growing interest in consolidating information and purchasing power more strongly, and exploring ways to reach deals that would cover all UK universities.

Pressure to cancel lowly used titles was immense everywhere and journal use monitoring is widely practised and in the case of one library shows that as much as one-quarter of big deal titles obtain less than six uses per year.

\section{Books/e-books}


Perhaps the major story in the Charleston data is the position of e-books which seem likely to be relatively sheltered from the coming storm, especially in corporate (mean rating $=1.9$ on a scale where $1=$ Less likely to be cut and $4=$ More likely to be cut) and public sector libraries (mean rating=2.0). However, in the focus groups, UK university librarians expressed their frustration with publishers who seem to be dragging their feet in making available good and sufficient textbooks in digital form and on terms that meet the needs of libraries and their users. Nevertheless, the focus groups also indicated that books generally are likely to obtain more protection from the worst of the cuts, probably because the availability of core texts, especially prescribed texts, is currently a critical issue in the UK: content is a major driver of student satisfaction, and that means books for students.

\section{Staffing}

The outlook for jobs is best in small libraries, libraries in the corporate sector and, more generally, for libraries in North America. The plight of UK university libraries looks bad. Nearly three quarters $(72.3 \%)$ of UK librarians anticipate making actual cuts in staffing, compared with only just over a quarter of US librarians; add to that the figure of $15 \%$ of UK academic librarians who expect cuts to be large; (the contrasting figure for the US was $8 \%$ )and one gets a real perspective on the scale of the problem.

The most likely mechanisms for achieving staff cuts everywhere are a freeze on recruitment and / or not filling vacant posts, rather than more direct measures such as forced redundancy, re-grading or restructuring. There are, of course, many issues to consider here, including human resource policies and national legislation, so the survey can only offer a very general picture.

According to the Charleston survey the significant differences in managing staff budgets between US and UK universities are that US librarians are more likely to opt for salary cuts and a cut in hours that staff work; UK librarians are more likely to opt for restructuring.

UK university librarians in the focus groups pointed out the problems involved in reducing the staff budget given that staffing levels are already pared to the bone (and SCONUL figures show that numbers are now declining). Nevertheless, they felt it was inevitable that further cuts would take place. Thin staffing models have prevailed because of years of cuts but university management often still perceives that libraries are full of expensive staff and that librarians' jobs are not always appropriate to their grade. In defence, librarians feel that there is a misunderstanding as to what staff actually do and contribute, and that it is librarians who are largely to blame for not communicating this. This might well have prompted one library to call its staff 'information consultants'.

Self-service, making use of technologies such as RFID (radio frequency identification) has been introduced in a number of institutions. It has been a means of delivering staff savings and efficiencies. But librarians believe that the scope for further savings is inevitably limited given the scale of the economic challenge, for even self-servicing requires staff somewhere along the information chain. 


\section{Services and infrastructure}

The Charleston survey showed that for a large majority of institutions in all sectors $(81.9 \%)$, there are no plans to cut library services or infrastructure over the coming two years. However, of those that are planning to make cuts, there are (significantly) more in the academic sector and fewer in the corporate sectors. As a general pattern, large libraries (26.7\%) are much more likely to be considering cuts in services and infrastructure than small libraries (5.9\%), presumably because they have more flexibility in these matters. There is very little geographic variation in these responses: cuts seem to be mainly a function of size and sector.

In those cases (18.1\%) where cuts are planned, the most vulnerable services are library opening hours (by some considerable margin), followed by reduced enquiry desk support. Part of the attraction of cuts of this kind is that their impact will be limited because of the growth of remote access to library content and services. There was little geographic variation in the nature of the responses to this question, although reduced opening hours are being considered as a 'very likely' option by $41.7 \%$ of North American libraries against a world average of $37.5 \%$ (these percentages relate only to that minority of libraries that were actually planning service or infrastructure cuts). IT and building projects seemed to be the least vulnerable to cuts.

With regard to the differences between UK and US academic libraries, US librarians are more likely to opt for reduced opening hours and UK ones to delay major IT projects.

The focus groups provided a possible explanation for the reluctance to shelve building projects. Capital investment is seen as a driver of student (and parental) satisfaction, especially for international students. New libraries are seen as iconic, something to boast about and market, so they are likely to be protected from cost-cutting. However, what concerns librarians is sustainability and whether you can fill the new buildings with resources and effective services, and users, given the constraints on resource spending and the digital transition.

\section{New Areas, Initiatives and Activities}

The objectives of our work were not simply to establish the financial impacts of the economic recession on libraries and to benchmark them, but also to see what positive actions and innovatory practices, if any, were emerging as a result of the financial challenges. Of course, most academic libraries have developed in the past decade new kinds of activities in supporting research, teaching and learning. And senior librarians are very much aware of the need to sustain the momentum of innovation in developing new approaches and new services to support changes in institutional missions and in the workflows of both students and staff. But there is a fear that the scope for doing so may become increasingly constrained by financial cuts and loss of key staff.

So far in this paper, we have considered librarians' responses to each issue in turn, independently of other questions in the survey. However, most decisions involve some kind of trade-off (you cannot have everything), and to examine this we have employed a 
technique called trade-off analysis. This is a method for attaching a numerical preference score to the different goals in a decision-making process in order to determine preferences in decreasing one or more goals or areas of activity in order to achieve an increase in another area. We achieved this in the survey by asking people to choose their most favoured and least favoured solution in a given situation (Max-Diff analysis), thus effectively ranking the components in preference order.

When consumers make a purchasing decision, for example when buying a new car, they have to weigh up a lot of different issues in their mind. Some features of a car, like engine size, brand or price, will weigh very heavily for most people. Other factors, like an in-car DVD or satnav system may be fairly important or fairly marginal, depending upon the individual's priorities. Other factors, like the colour of the upholstery may scarcely register at all with some people (but not all). These preferences that underlie a purchasing decision can be modeled. On a scale of 100, it is quite probable that most consumers would rate engine size very high, and give upholstery colour a very low weighting. Trade-off analysis is a method for attaching a numerical preference score to the different attributes of a decision process in complex situations like this. The graphics that follow show the preferences of senior librarians when weighing up the options. The numbers are abstractions without associated units. They add up to 100 for the sake of convenience. They are not percentages of individuals that 'voted' for a single solution. They offer an insight into a decision making process by a large group of survey respondents and show the relative weighting that they put on the key issues.

One of the most obvious, albeit not the easiest, things librarians can do to get themselves out of their financial difficulties is to seek sources of additional funding. Figure 4 shows the results for three possible routes to secure additional funds, and these were presented to UK and US university librarians. The differences could not be more marked, with US librarians exhibiting a strong leaning towards introducing higher user charges and the UK ones believing that arguing internally for a greater share of the budget would yield better dividends. The focus groups provided the reasons for the difference. Many UK university libraries gain no benefit from the income they generate from internal sources, which is returned to central university funds. And on the whole, they see relatively little scope in the current climate for increasing their income from either internal or external sources. Fines are also unpopular with students; project income from sources such as JISC is likely to be increasingly constrained; and external fundraising has to be carefully coordinated with the institution.

\section{Figure 4: Trade off analysis: ways of seeking additional funding ${ }^{1}$}

\footnotetext{
1 The numbers in Figures 4-7 are the relative weights that library directors placed on the issues identified in each graphic. These weights were derived using a technique known as conjoint analysis. Conjoint analysis involves the measurement of psychological judgments (such as preferences), between various alternatives. In this study, users were asked to rank combinations of attributes in order to determine the relative importance assigned to individual attributes. By isolating the attributes, we can
} 
$(n=360 \mathrm{US} / \mathrm{UK}$ academic libraries)
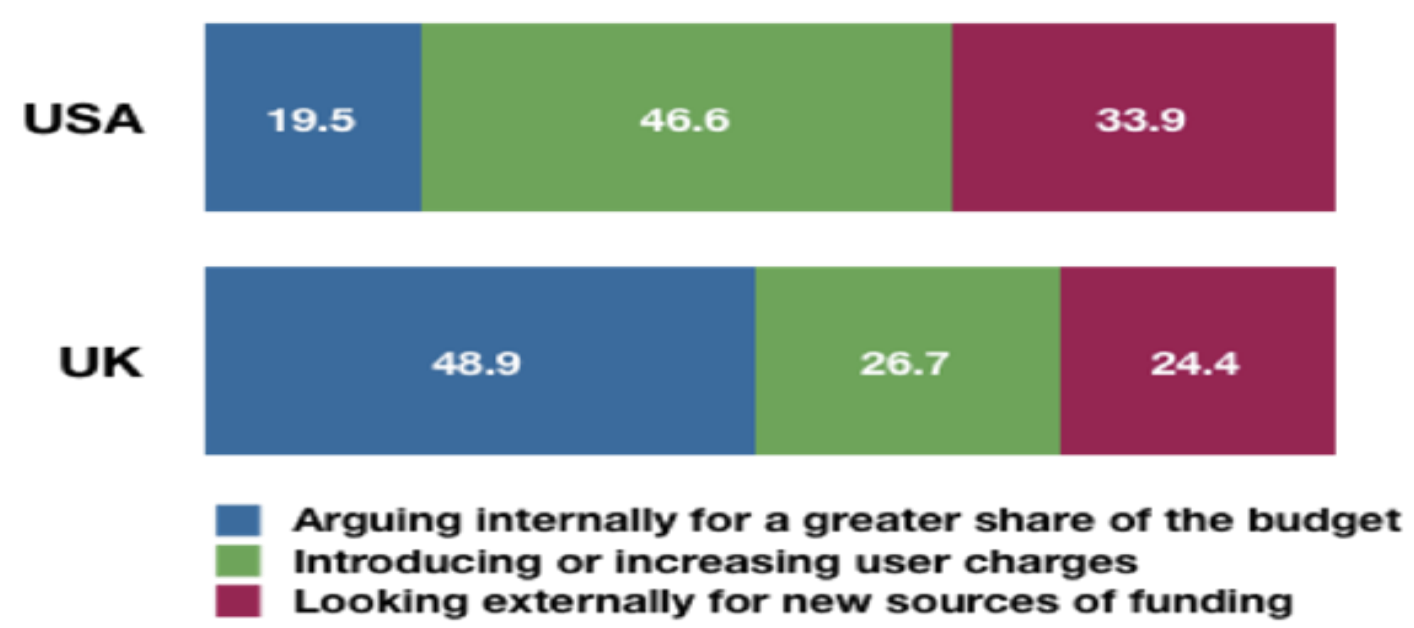

Another approach open to university librarians would be to do things differently and the responses to three possible opportunities are reported in Figure 5. Again there are large differences between US and UK university librarians, with the former believing much more strongly that accelerating the move from print to digital is the best approach. There appears to be an implicit recognition here that e is 'cheaper' and it has to be asked how well founded that belief really is. UK librarians, on the other hand, think there is relatively more mileage in directing users to free content, courtesy of OA sources, and in outsourcing library services and infrastructure. The focus on open access derives in part from the JISC's strong support (financially) for OA and institutional repository initiatives.

Figure 5: Trade off analysis: doing things differently $(n=360 \mathrm{US} / \mathrm{UK}$ academic libraries)

more effectively see which ones are affecting their decision-making process especially in complex scenarios like this. 
USA

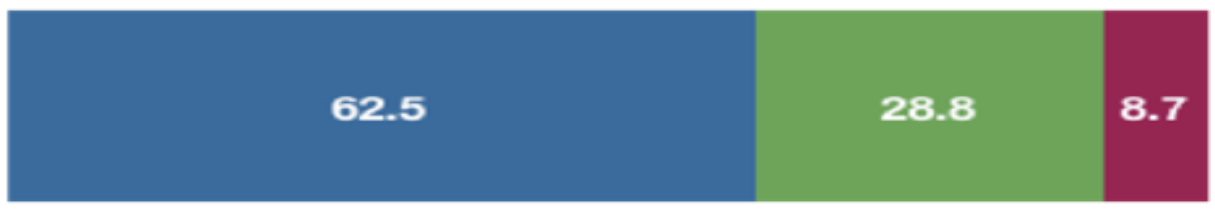

UK

Accelerating the move from print to electronic Directing users to free electronic resources Outsourcing library services or infrastructure 
Responses to the Charleston survey indicated that sustaining momentum will depend increasingly on co-operation across the sector, and the topic of sharing services emerged as a strong talking point in the focus groups.. This is an area, however, where it is difficult to make international comparisons, since universities are organised and funded in quite different ways. In the US, for example, there are many more private sector universities than in the UK, and the public universities are organised at state rather than federal level. In the UK, on the other hand, despite the emphasis on university autonomy, there is a strong culture which favours co-operation between libraries.

In this context, US librarians indicated in the Charleston survey a belief that co-operation would deliver resource savings, nothing else. UK university librarians attending the focus groups, by contrast, were strongly in favour of shared service provision and questioned why each individual library should have to wrestle with its own Library and Electronic Resource Management Systems. They believe there is a need to co-operate more, especially in the field of cataloguing. As one participant asked, 'Why oh why does everyone catalogue the same book in this day and age? It is crazy that we don't do this nationally'; more than a hundred institutions all cataloguing the same book!' They also believe that there is scope for co-operation in the provision of information literacy training.

The third set of options presented in the Charleston survey covered the possibilities for introducing smarter management, with 4 options were offered for consideration (Figure 6). On both sides of the Atlantic, responses indicated that the best option would be to demonstrate value through better usage and outcomes data. This finding is interesting not least because it suggests that librarians feel they are doing a useful job, but one which they find difficult to demonstrate. Getting a better sense of value is closely associated, of course, with getting a better understanding of costs, though UK librarians are rather more optimistic than their US colleagues that this will help bring the dividends they seek. And both in the US and the UK, librarians put significant emphasis on seeking to reduce costs by putting pressure on vendors over pricing. But the survey and the focus groups both give a strong sense that librarians are seeking a better understanding of the value proposition they offer to their universities, and of the linkages between their inputs and the teaching, learning and research outcomes that are achieved with their support. They thus need tools to make better sense of their environment, and to construct more powerful arguments to convince the senior managers in their universities of the value they provide.

\section{Figure 6: Trade off analysis: smarter management (n=360 US/UK academic libraries)}



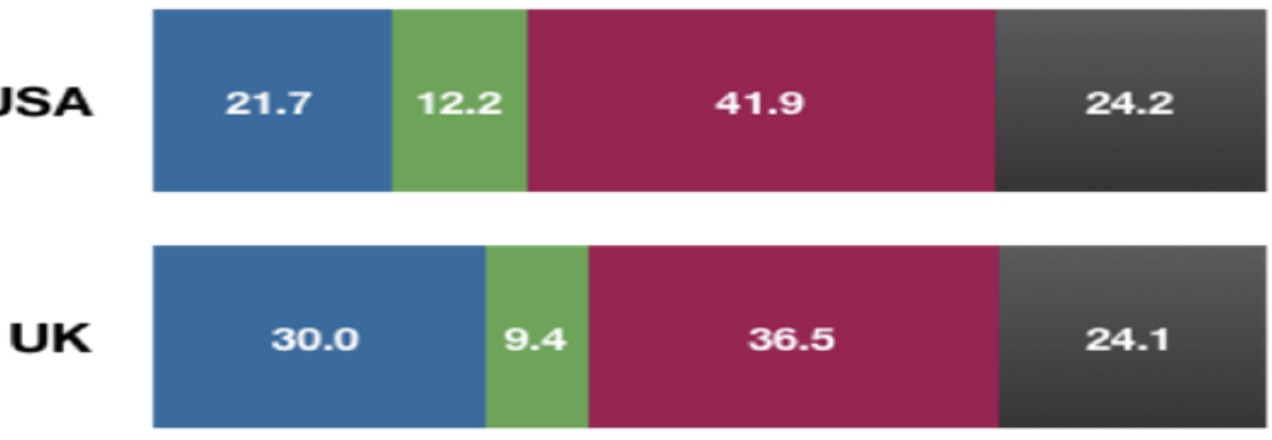

\section{Getting a better understanding of your costs More effective benchmarking and performance indicators Demonstrating value through better usage and outcomes data Putting greater pressure on vendors over pricing}

Overall, librarians are positive about the need for change, and see doing things differently as the best option in responding to budgetary pressures as well as changes in the information and higher education environments.

\section{Conclusion}

Academic libraries have demonstrated their ability to lead and to adapt their roles in response to changing circumstances. They play a crucial role in supporting the teaching, learning and research missions of their universities. The quality of libraries and their services is an especially-important part of the student experience, and students are increasingly vocal about any perceived shortcomings.

Librarians recognise that they must respond to the pressures of a new period of financial stringency, and demonstrate that their services are both efficient and effective in delivering value to the staff and students in their universities. Directors are thus very open to the suggestion that they should find ways of doing things differently; and many of them see budget cuts as an opportunity to re-think what the library does and what it means. But there are as yet few concrete proposals that will transform services or yield large-scale efficiency savings, at least within the bounds of individual universities. In these circumstances, it is important for libraries to share ideas and experiences, and to test what works and what does not. They must also exploit the potential for co-operation in developing a range of shared services in order to enhance efficiency, as well as the scope and quality of what they provide to both academic staff and students.

Libraries need to do all this not least in order to sustain a momentum in the development of new services that meet the changing needs of users and the missions and strategies of their host universities. Co-operation and partnership - with other libraries; with other information service providers; and with the staff, students and senior managers of their host universities - will be watchwords for libraries as they develop their strategies for the future. Working closely together with, and influencing, partners across the university 
sector will be essential if libraries are to exploit the current financial difficulties as an opportunity for change.

\section{Acknowledgments}

The work reported here was funded by eBrary, Taylor \& Baker and the Research Information Network. Thanks also to Katina Strauch of The Charleston Conference and SCONUL for their support.

\section{Notes and References}

1. http://www.katina.info/conference/

2. http://www.rin.ac.uk

3. http://www.jisc.ac.uk/news/stories/2009/10/librarycc.aspx

4. Visit these addresses:

i. http://www.jisc.ac.uk/publications/documents/libsitimpacts.aspx

ii. http://www.alpsp.org/ngen_public/article.asp?id=335\&did=47\&aid=36178\&st=\&oaid=-1

iii. http://uksg.metapress.com/openurl.asp?genre=article\&id=doi:10.1629/22113

5. Of course publishers could claim much in this regard.

\section{Further information and resources to complete}

CIBER, The economic downturn and libraries: Survey findings, available at http://www.ucl.ac.uk/inforstudies/research/ciber/charleston-survey.pdf

RIN, Overcoming barriers: access to research information content, available at http://www.rin.ac.uk/system/files/attachments/Sarah/Overcoming-barriers-reportDec09_0.pdf

RIN, E-journals: their use, value and impact, available at http://www.rin.ac.uk/system/files/attachments/sarah/E-journals-report.pdf

RIN, Ensuring a bright future for research libraries, available at http://www.rin.ac.uk/system/files/attachments/sarah/Ensuring-bright-future-librariesguidance.pdf

JISC, The impact of the economic recession on university library and IT services available at http://www.jisc.ac.uk/media/documents/publications/briefingpaper/2009/bprecession-v1-03-tagged.pdf 